OPEN ACCESS

Edited by:

Xingtao $\mathrm{Xu}$,

National Institute for Materials

Science, Japan

Reviewed by:

Qian Li,

Shanghai Jiao Tong University, China

Tairui Zhang

Japan Atomic Energy Agency, Japan

*Correspondence:

Xun Sun

xunsun@sdu.edu.cn

Specialty section

This article was submitted to

Nanoscience,

a section of the journal

Frontiers in Chemistry

Received: 01 March 2020

Accepted: 17 March 2020

Published: 15 April 2020

Citation:

Sun X, Chen S, Liu J, Zhao S and Yoon JY (2020) Hydrodynamic Cavitation: A Promising Technology for Industrial-Scale Synthesis of

Nanomaterials. Front. Chem. 8:259.

doi: 10.3389/fchem.2020.00259

\section{Hydrodynamic Cavitation: A Promising Technology for Industrial-Scale Synthesis of Nanomaterials}

\author{
Xun Sun ${ }^{1 *}$, Songying Chen ${ }^{1}$, Jingting Liu ${ }^{1}$, Shan Zhao ${ }^{2}$ and Joon Yong Yoon ${ }^{3}$ \\ ${ }^{1}$ Key Laboratory of High Efficiency and Clean Mechanical Manufacture, Ministry of Education, National Demonstration Center \\ for Experimental Mechanical Engineering Education at Shandong University, School of Mechanical Engineering, Shandong \\ University, Jinan, China, ${ }^{2}$ Shandong Key Laboratory of Water Pollution Control and Resource Reuse, School of \\ Environmental Science and Engineering, Shandong University, Qingdao, China, ${ }^{3}$ Department of Mechanical Engineering, \\ Hanyang University, Ansan, South Korea
}

One of the most challenging issues for the large-scale application of nanomaterials, especially nanocarbons, is the lack of industrial synthetic methods. Sonochemistry, which creates an extreme condition of high pressure and temperature, has been thereby applied for synthesizing a wide variety of unusual nanostructured materials. Hydrodynamic cavitation $(\mathrm{HC})$, characterized by high effectiveness, good scalability, and synergistic effect with other physical and chemical methods, has emerged as the promising sonochemistry technology for industrial-scale applications. Recently, it was reported that $\mathrm{HC}$ can not only significantly enhance the performance of biochar, but also preserve or improve the respective chemical composition. Moreover, the economic efficiency was found to be at least one order of magnitude higher than that of conventional methods. Due to the great potential of $\mathrm{HC}$ in the industrial-scale synthesis of nanomaterials, the present perspective focuses on the mechanism of sonochemistry, advances in $\mathrm{HC}$ applications, and development of hydrodynamic cavitation reactors, which is supposed to contribute to the fundamental understanding of this novel technology.

\section{Keywords: sonochemistry, synthesis of nanomaterials, hydrodynamic cavitation, hydrodynamic cavitation reactor,} application potentiality

\section{INTRODUCTION}

The concept of nanoscience and nanotechnology was first proposed by Richard Feynman in 1959 (Feynman, 1992). Until 1974, the term nanotechnology (Taniguchi, 1974) was introduced by Nario Taniguchi during a scientific conference. With the help of the scanning tunneling microscope, which was invented by Gerd Binnig and Heinrich Rohrer in 1981 (Binnig and Rohrer, 1987), the modern nanotechnology has been developing rapidly since then. Recent advances in nanomaterials have significantly influenced various fields, e.g., material science, medical science, environmental science, magnetics, mechanics, and optics. Because the synthesis method largely determines the physical properties and applications of nanomaterials, developing new methods to design appropriate synthetic routes has been the research hotspot (Wang et al., 2019; Xu et al., 2019). Among the diverse physical and chemical synthesis methods, sonochemistry method has been considered one of the most powerful tools for synthesizing nanomaterials (Bang and Suslick, 2010). 
Sonochemistry can be effectively induced by ultrasounds (i.e., acoustic cavitation, AC) or local pressure drop (i.e., hydrodynamic cavitation, HC). AC has been utilized to achieve a wide variety of unusual nanostructured materials at laboratory scale, e.g., metals, metal oxides, metal chalcogenides and carbides, carbon, protein, and polymer. However, further application in industrial-scale may be considerably difficult as the issues of scale-up and energy efficiency (Gagol et al., 2018). Recently, $\mathrm{HC}$, which has emerged as the promising technology for various industrial-scale applications, was found to be an effective tool for synthesis of nanomaterials through mechanisms similar to that of AC. The present paper aims to discuss the mechanism of sonochemistry, recent advances in the HC technology development, and its application perspective for synthesis of nanomaterials.

\section{SONOCHEMISTRY}

Unlike traditional energy sources such as heat, light, or ionizing radiation that are required for chemical reactions to proceed, sonochemistry is a unique energy-matter interaction that occurs without direct interaction with molecular species (Thompson and Doraiswamy, 1999). Sonochemistry derives principally from cavitation which is a rapid phase-change phenomenon in liquids, consisting of growth and collapse of cavitation nuclei during an extremely short period (Suslick, 1990). When the bubble collapses, a huge amount of energy, on the order of $1-10^{18}$ $\mathrm{kW} / \mathrm{m}^{3}$, can be released into surrounding liquids (Gogate et al., 2006). The released energy can be divided into three forms (Sun et al., 2018b).

Mechanical effect: Generation of shock waves with propagation velocities of $2,000 \mathrm{~m} / \mathrm{s}$ in average (Holzfuss et al., 1998), micro-jets with high water-hammer pressure (450 MPa;Vogel et al., 1989) and velocity (over $120 \mathrm{~m} / \mathrm{s}$; Benjamin and Ellis, 1966; Lauterborn and Bolle, 1975; Shima et al., 1981), and high shear stresses (as high as $3.5 \mathrm{kPa}$; Dijkink and Ohl, 2008).

Thermal effect: Production of local hot spots (2,000-6,000 K, depending on the distance; Hart et al., 1990; Flint and Suslick, 1991; Didenko et al., 1999) with heating/cooling rates $>10^{10} \mathrm{~K} / \mathrm{s}$ (Suslick et al., 1986).

Chemical effect: Formation of highly active hydroxyl radicals, with an oxidation potential of $2.8 \mathrm{~V}$, by the sonolysis of water molecules (Arrojo et al., 2007; Kuppa and Moholkar, 2010).

The combination of the above three effects creates extreme conditions for synthesis of nanomaterials at ambient conditions (e.g., room temperature and atmospheric pressure) and sometimes even without the utilization of catalysts. Taking synthesizing nanostructured carbon materials as an example, sonochemistry effect can not only enhance the reactions which can lead to exotic carbon nanostructures (Sun et al., 2002), but also induce dramatic morphology changes in pre-synthesized carbon materials (Viculis et al., 2003). However, due to the characteristics of AC, the energy density rapidly attenuates with increasing distance from the ultrasonic horn and disappears at a distance of as low as $2-5 \mathrm{~cm}$ (Gagol et al., 2019). Therefore, to achieve the desired energy density, a number of ultrasonic horns have to be closely arranged in an AC reactor. This inherent feature of AC causes the equipment prices and operational costs rise rapidly with the scale (Gagol et al., 2018), which indicates that $\mathrm{AC}$ is not suitable for industrial-scale synthesis of nanomaterials. On the other hand, HC, which can effectively induce sonochemistry by utilizing a mechanical approach, has the ability to overcome the inherent defect of AC.

\section{HYDRODYNAMIC CAVITATION}

Unlike AC, which is generated by applying ultrasound waves with a cyclic succession of expansion (rarefaction) and compression phases on a liquid (Vajnhandl and Majcen Le Marechal, 2005), $\mathrm{HC}$ is induced by static pressure drops of the flowing liquid. When the flow passes through constricted parts or irregular geometries, the flow velocity increases and then, a decrease in static pressure can be caused. Once the pressure falls below the local saturated vapor pressure, cavitation nuclei existing in water begin to grow because their internal pressures become greater than the surface tension. When the flow pressure recovers, the growing nuclei become unstable and collapse (Yan and Thorpe, 1990). The working principle of a typical HC system (Venturi) is shown in Figure 2A (Šarc et al., 2018). The liquids in the reservoir are pumped to the Venturi section, cavitation phenomenon occurs in the diffusion part of the Venturi, and then, the liquids are sent back to the reservoir. The above process will continue for a period of time until the satisfactory treatment effect is obtained.

The exploration of $\mathrm{HC}$ began at the beginning of the 20th century as a negative consequence of erosion damage. In 1912, Silberrad reported that cavitation was associated with severe destructive damage to the propellers of the great ocean liners Lusitania and Mauretania (Silberrad, 1912). Since then, the researchers have been focusing on the negative effect of cavitation, e.g., performance losses of various fluid machinery, noise, and erosion damage (Rahmeyer, 1981; Sun et al., 2017b). On the other hand, Save et al. (1994) presented the first case study for microbial cell disruption by utilizing HC in 1994. After that, the applications of HC have begun to attract attention in a wide variety of areas, especially in the last few years (Figure 1). Nowadays, researchers have found that $\mathrm{HC}$ can be an effective tool for a number of chemical, biological, and other types of applications, e.g., microbial inactivation [bacteria (Mane et al., 2020), algae (Waghmare et al., 2019), virus (Kosel et al., 2017)], the removal of organic compounds (acids Choi et al., 2019, antibiotics (Tao et al., 2018), pesticides (Panda and Manickam, 2019), dyes Yi et al., 2018, pharmaceuticals (Rajoriya et al., 2019), fuel (Torabi Angaji and Ghiaee, 2015), phenols Chakinala et al., 2008, etc.,) decomposition of wasteactivated sludge (WAS) (Nabi et al., 2019), depolymerization (Prajapat and Gogate, 2019), denitrification (Song et al., 2019), desulfurization (Gagol et al., 2019), fibrillation (Kosel et al., 2019), intensification of biogas production (Zielinski et al., 2019), biofuel synthesis (Chipurici et al., 2019), liposome destruction (Pandur et al., 2020), catalyst slurry preparation 


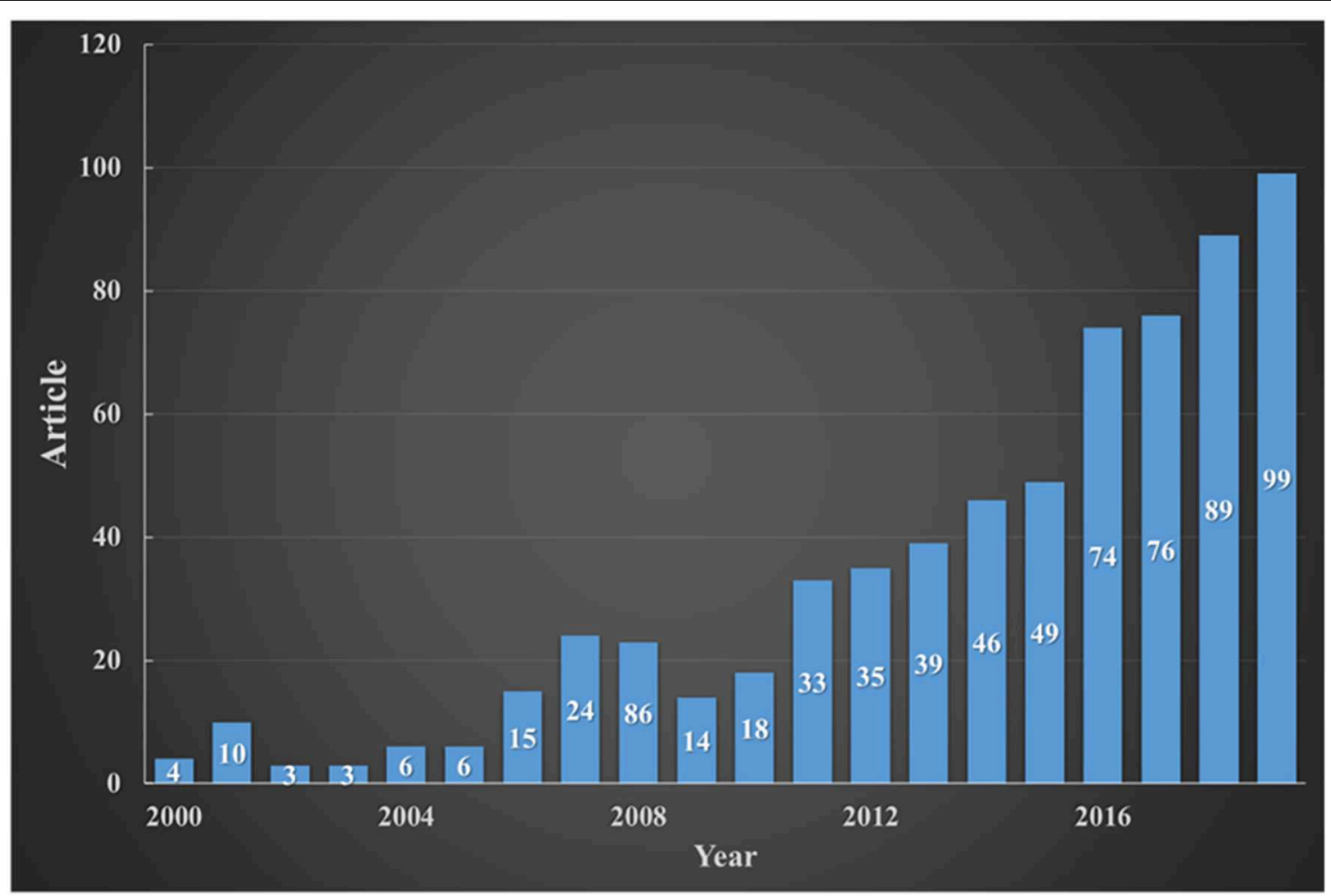

FIGURE 1 | Articles about HC application from 2000 to 2019 (based on Google Scholar available on 25.2.2020).

(Kuroki et al., 2019), flotation (Ross et al., 2019), food processing (Terán Hilares et al., 2019), surface finishing (Nagalingam et al., 2019), viscosity reduction (Gregersen et al., 2019), residual stress relief, cleaning, and emulsification (Wu et al., 2019).

Until last year, the first study on the nanomaterial preparation by utilizing $\mathrm{HC}$ was reported by Albanese et al. (2019) who utilized $\mathrm{HC}$ to enhance the surface area of biochar by as much as $120 \%$, while preserving or improving the respective chemical composition. The increases in functionality and porosity of the biochar were contributed to the effect of the physical impact and oxidation (hydroxyl radicals) of HC. Moreover, the economic efficiency was found to be at least one order of magnitude higher than that of the conventional method, which demonstrates that $\mathrm{HC}$ can be an effective alternative approach for synthesis of nanomaterials. HC phenomenon is induced by hydrodynamic cavitation reactor (HCR), i.e., the container for $\mathrm{HC}$ reaction, therefore, the $\mathrm{HC}$ generation efficiency of HCR determines the treatment effect, economy, and applicability of HC technology. To accelerate the development of HC-based synthetic strategies of industrialscale production of nanomaterials, the most important thing is to develop new-family HCRs. Therefore, we further make a simple overview of the development of HCR in order to give readership more clearer understandings about this new field.

\section{DEVELOPMENT OF HCR}

HCRs can be generally categorized into two types based on their operational mechanism: non-rotational and rotational. In common conventional HCRs [CHCRs, e.g., Venturi type (Figure 2B; Jančula et al., 2014) and orifice type], low-pressure separation region can be formed when the fluid passes through the contractive portion where the static pressure is converted to kinetic energy (Merzkirch et al., 2015). To understand the mechanisms of HC treatment, CHCRs have been widely utilized in laboratory scale in the previous studies, because of the advantages they offer in simple design, lack of moving parts, and ease of manufacture and use (Dular et al., 2016). Moreover, some researchers found that $\mathrm{CHCRs}$ can be applied to real industrial applications (Hirooka et al., 2009).

Recently, a few rotor-stator type HCRs (R-S HCRs) have been introduced in the literature. R-S HCRs utilize a circular disk or cylinder with numerous gaps to generate cavitation (Figure 2C; Zupanc et al., 2014). Due to the viscosity, the fluid is driven by the rotor and the flow direction is identical to the rotational direction. The flow punches the back edge of the gap and forms separation region with low pressure. Cavitation bubbles can occur when the rotational speed reaches the critical value. The results from the corresponding research indicated the effectiveness of the treatment, economic efficiency which is far beyond those of traditional devices in the removal 

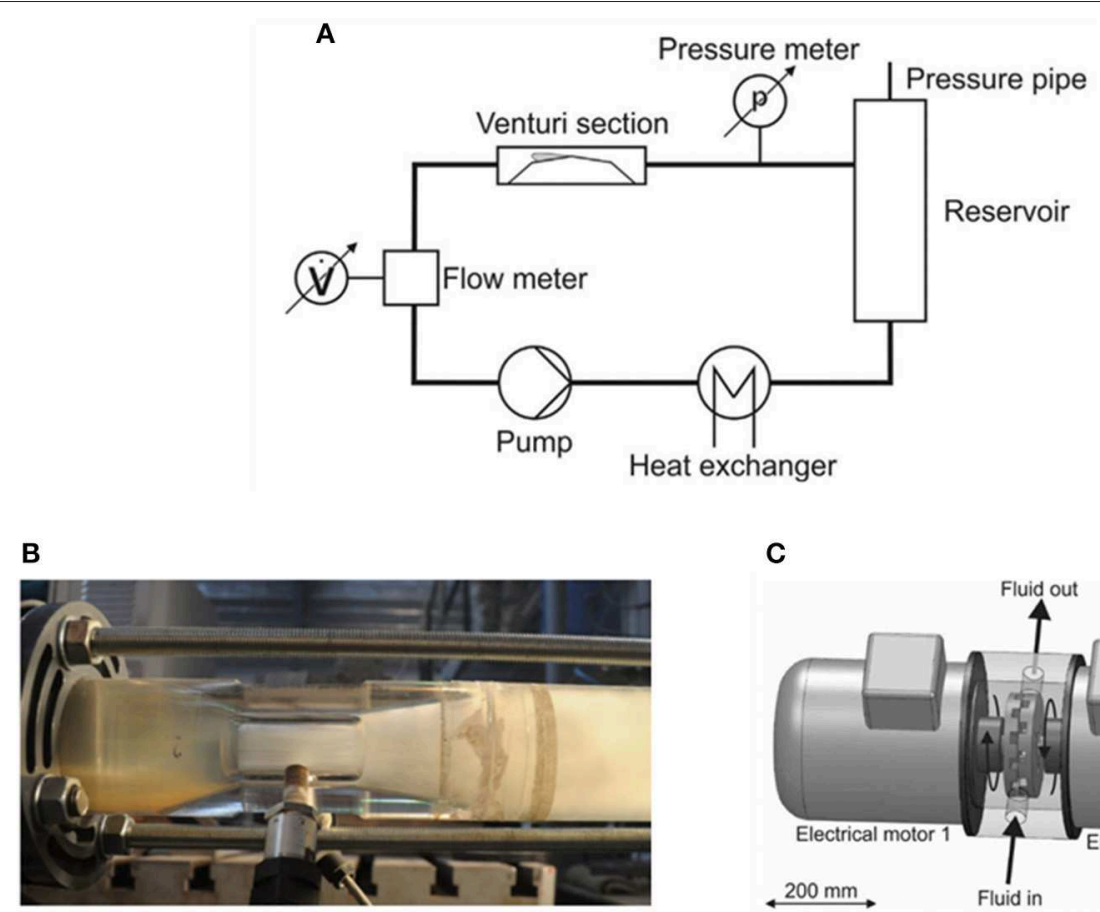

C

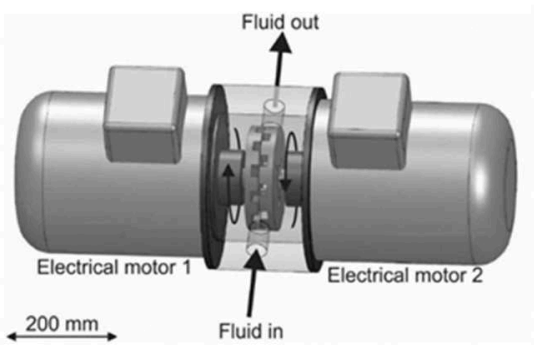

FIGURE 2 | Schematic diagram of representative HC working principle (A) Šarc et al. (2018) and HCRs, (B) Venturi, and (C) rotor-stator type (Zupanc et al., 2014).

of microorganism (Milly et al., 2007, 2008; Šarc et al., 2018; Sun et al., 2018a,b; Maršálek et al., 2020), WAS treatment (Petkovšek et al., 2015; Kim et al., 2019, 2020; SeŽun et al., 2019), organic wastewater treatment (Badve et al., 2013; Zupanc et al., 2014), biofuel synthesis (Mohod et al., 2017; Chipurici et al., 2019), fibrillation (Kosel et al., 2019), intensification of biogas production (Patil et al., 2016), and delignification (Badve et al., 2014), etc., even without geometrical optimization or in scaled-up application. In addition, due to the extreme conditions and the hydroxyl radicals produced by HC, effective synergic effects between HC and heating, AC (Sun et al., 2018a), various oxidants (Saharan et al., 2011), photocatalyst (Wang et al., 2011), photolysis (Zupanc et al., 2014), and electrochemical (Wang et al., 2010) have been proved. More importantly, it is worth noting that R-S HCRs show promising scalability (Joshi and Gogate, 2019), and their performance can be easily improved by scaling up the dimensions, which was confirmed by Sun et al. (2018a) who found that when the rotor of the HCR doubled in size (290$590 \mathrm{~mm}$ ), heat generation and thermal efficiency increased from 48 to $200 \mathrm{MJ} / \mathrm{h}$ and 82 to $91 \%$, respectively.

So far, HC technology has not been widely utilized in industrial applications around the world, even though it has been investigated and developed for nearly 30 years. Most of the existing research relates to applications, the characteristics of HCRs have been rarely focused, which largely influences the development and application of HC technology. Even though a few researchers have made important contributions in theoretical (Sarvothaman et al., 2019), computational (Badve et al., 2015), and experimental (Zhang et al., 2018) aspects of HCRs, their cavitation generation mechanism, internal flow fields, external characteristics, and scale-up law are not well understood by utilizing experimental flow visualization, particle image velocimetry, and computational fluid dynamic methods, especially for the R-S HCRs. More importantly, the universal research and design methods (e.g., the theoretical and numerical methods for design the rotor, stator, and flow path, scale-up law, and optimization method) for HCRs have not been established yet. The investigations on the internal fluid field, geometrical optimizations, numerical simulation methods, dimensional analyses, and similarity laws for the external characteristics, etc., are required in future.

\section{CONCLUSION AND PERSPECTIVE}

The present paper illustrated the mechanism of sonochemistry, advances in HC applications, and development of hydrodynamic cavitation reactors, with the aim to contribute to the fundamental understanding of this novel technology. With the mechanism similar to that of AC, HC technology appears to be an effective sonochemistry means for synthesizing nanomaterials in industrial-scale due to its good scalability. The development and application of $\mathrm{HC}$ synthetic method will be a real challenge because of its highly interdisciplinary (related to sonochemistry, fluid dynamics, material science, and mechanical engineering). However, significant progress in this technology will lead to the considerable promotion of the industrialization of nanomaterials. Several challenges and research directions that can be considered are outlined below: 
- To understand the HC mechanism, it is necessary to apply HC to the preparation of various types of nanomaterials, including metals, alloys, oxides, sulfides, carbides, carbons, polymers, and biomaterials.

- Studying the synergistic effects between HC and traditional synthetic methods on the structure and performance of nanomaterials.

- Developing appropriate CFD methods to reveal the cavitation generation mechanism and design new HCRs.

- Optimizing the geometrical structure of HCRs by advanced algorithms (Sun et al., 2017a; Sun and Yoon, 2018).

- Establishing the universal research and design methods for HCRs.

\section{DATA AVAILABILITY STATEMENT}

All datasets generated for this study are included in the article/supplementary material.

\section{REFERENCES}

Albanese, L., Baronti, S., Liguori, F., Meneguzzo, F., Barbaro, P., and Vaccari, F. P. (2019). Hydrodynamic cavitation as an energy efficient process to increase biochar surface area and porosity: a case study. J. Clean. Prod. 210, 159-169. doi: 10.1016/j.jclepro.2018.10.341

Arrojo, S., Nerín, C., and Benito, Y. (2007). Application of salicylic acid dosimetry to evaluate hydrodynamic cavitation as an advanced oxidation process. Ultrason. Sonochem. 14, 343-349. doi: 10.1016/j.ultsonch.2006.06.007

Badve, M., Gogate, P., Pandit, A., and Csoka, L. (2013). Hydrodynamic cavitation as a novel approach for wastewater treatment in wood finishing industry. Sep. Purif. Technol. 106, 15-21. doi: 10.1016/j.seppur.2012.12.029

Badve, M. P., Alpar, T., Pandit, A. B., Gogate, P. R., and Csoka, L. (2015). Modeling the shear rate and pressure drop in a hydrodynamic cavitation reactor with experimental validation based on KI decomposition studies. Ultrason. Sonochem. 22, 272-277. doi: 10.1016/j.ultsonch.2014.05.017

Badve, M. P., Gogate, P. R., Pandit, A. B., and Csoka, L. (2014). Hydrodynamic cavitation as a novel approach for delignification of wheat straw for paper manufacturing. Ultrason. Sonochem. 21, 162-168. doi: 10.1016/j.ultsonch.2013.07.006

Bang, J. H., and Suslick, K. S. (2010). Applications of ultrasound to the synthesis of nanostructured materials. Adv. Mater. 22, 1039-1059. doi: 10.1002/adma.200904093

Benjamin, T. B., and Ellis, A. T. (1966). The Collapse of cavitation bubbles and the pressures thereby produced against solid boundaries. Philos. Transact. Royal Soc. London. Series A, Math. Phy. Sci. 260, 221-240. doi: 10.1098/rsta.1966.0046

Binnig, G., and Rohrer, H. (1987). Scanning tunneling microscopy-from birth to adolescence. Rev. Mod. Phys. 59:615. doi: 10.1103/RevModPhys.59.615

Chakinala, A. G., Bremner, D. H., Gogate, P. R., Namkung, K.-C., and Burgess, A. E. (2008). Multivariate analysis of phenol mineralisation by combined hydrodynamic cavitation and heterogeneous advanced Fenton processing. Appl. Catal. B: Environ. 78, 11-18. doi: 10.1016/j.apcatb.2007.08.012

Chipurici, P., Vlaicu, A., Calinescu, I., Vinatoru, M., Vasilescu, M., Ignat, N. D., et al. (2019). Ultrasonic, hydrodynamic and microwave biodiesel synthesis a comparative study for continuous process. Ultrason. Sonochem. 57, 38-47. doi: 10.1016/j.ultsonch.2019.05.011

Choi, J., Cui, M., Lee, Y., Ma, J., Kim, J., Son, Y., et al. (2019). Hybrid reactor based on hydrodynamic cavitation, ozonation, and persulfate oxidation for oxalic acid decomposition during rare-earth extraction processes. Ultrason. Sonochem. 52, 326-335. doi: 10.1016/j.ultsonch.2018.12.004

Didenko, Y. T., McNamara, W. B., and Suslick, K. S. (1999). Hot spot conditions during cavitation in water. J. Am. Chem. Soc. 121, 5817-5818. doi: $10.1021 /$ ja 9844635

\section{AUTHOR CONTRIBUTIONS}

XS, JY, and SC contributed conception of the study. XS produced and wrote the article. JL and SZ edited the article.

\section{FUNDING}

This work was supported by the National Natural Science Foundation of China (No. 51906125), China Postdoctoral Science Foundation (No. 2019M650162), Youth Interdisciplinary Science and Innovative Research Groups of Shandong University (No. 2020QNQT014), Young Scholars Program of Shandong University, Fundamental Research Funds of Shandong University (Nos. 2019HW027 and 2018GN033), Key Laboratory of High-efficiency and Clean Mechanical Manufacture at Shandong University, Ministry of Education, and Ocean Industry Leading Talent Team of Yantai's Double Hundred Plan.

Dijkink, R., and Ohl, C.-D. (2008). Measurement of cavitation induced wall shear stress. Appl. Phys. Lett. 93, 254107. doi: 10.1063/1.3046735

Dular, M., Griessler-Bulc, T., Gutierrez-Aguirre, I., Heath, E., Kosjek, T., Krivograd Klemenčič, A., et al. (2016). Use of hydrodynamic cavitation in (waste)water treatment. Ultrason. Sonochem. 29, 577-588. doi: 10.1016/j.ultsonch.2015.10.010

Feynman, R. P. (1992). There's plenty of room at the bottom. J. Microelectromech. Systems 1, 60-66. doi: 10.1109/84.128057

Flint, E. B., and Suslick, K. S. (1991). The temperature of cavitation. Science 253, 1397-1399. doi: 10.1126/science.253.5026.1397

Gagol, M., Przyjazny, A., and Boczkaj, G. (2018). Wastewater treatment by means of advanced oxidation processes based on cavitation - a review. Chem. Eng. J. 338, 599-627. doi: 10.1016/j.cej.2018.01.049

Gagol, M. R., Soltani, D. C., Przyjazny, A., and Boczkaj, G. (2019). Effective degradation of sulfide ions and organic sulfides in cavitationbased advanced oxidation processes (AOPs). Ultrason. Sonochem. 58:104610. doi: 10.1016/j.ultsonch.2019.05.027

Gogate, P. R., Tayal, R. K., and Pandit, A. B. (2006). Cavitation: a technology on the horizon. Curr. Sci. 91, 35-46. Available online at: https://www.currentscience. ac.in/php/toc.php?vol=091\&issue $=01$

Gregersen, S. B., Wiking, L., Bertelsen, K. B., Tangsanthatkun, J., Pedersen, B., Poulsen, K. R., et al. (2019). Viscosity reduction in concentrated protein solutions by hydrodynamic cavitation. Int. Dairy J. 97, 1-4. doi: 10.1016/j.idairyj.2019.04.015

Hart, E. J., Fischer, C.-H., and Henglein, A. (1990). Sonolysis of hydrocarbons in aqueous solution. Int. J. Radiat. Appl. Instrum. Part Radiat. Phy. C Chem. 36, 511-516. doi: 10.1016/1359-0197(90)90198-Q

Hirooka, K., Asano, R., Yokoyama, A., Okazaki, M., Sakamoto, A., and Nakai, Y. (2009). Reduction in excess sludge production in a dairy wastewater treatment plant via nozzle-cavitation treatment: Case study of an on-farm wastewater treatment plant. Bioresour. Technol. 100, 3161-3166. doi: 10.1016/j.biortech.2009.01.011

Holzfuss, J., Rüggeberg, M., and Billo, A. (1998). Shock wave emissions of a sonoluminescing bubble. Phys. Rev. Lett. 81, 5434-5437. doi: 10.1103/PhysRevLett.81.5434

Jančula, D., Mikula, P., Maršálek, B., Rudolf, P., and Pochylý, F. (2014). Selective method for cyanobacterial bloom removal: hydraulic jet cavitation experience. Aquacult. Int. 22, 509-521. doi: 10.1007/s10499-0139660-7

Joshi, S. M., and Gogate, P. R. (2019). Intensification of industrial wastewater treatment using hydrodynamic cavitation combined with advanced oxidation at operating capacity of 70 L. Ultrason. Sonochem. 52, 375-381. doi: 10.1016/j.ultsonch.2018.12.016 
Kim, H., Koo, B., Sun, X., and Yong Yoon, J. (2020). Investigation of sludge disintegration using rotor-stator type hydrodynamic cavitation reactor. Sep. Purif. Technol. 240:116636. doi: 10.1016/j.seppur.2020.116636

Kim, H., Sun, X., Koo, B., and Yoon, J. Y. (2019). Experimental investigation of sludge treatment using a rotor-stator type hydrodynamic cavitation reactor and an ultrasonic bath. Processes 7:790. doi: 10.3390/pr7110790

Kosel, J., Gutiérrez-Aguirre, I., Rački, N., Dreo, T., Ravnikar, M., and Dular, M. (2017). Efficient inactivation of MS-2 virus in water by hydrodynamic cavitation. Water Res. 124, 465-471. doi: 10.1016/j.watres.2017.07.077

Kosel, J., Šinkovec, A., and Dular, M. (2019). A novel rotation generator of hydrodynamic cavitation for the fibrillation of long conifer fibers in paper production. Ultrason. Sonochem. 59:104721. doi: $10.1016 /$ j.ultsonch.2019.104721

Kuppa, R., and Moholkar, V. S. (2010). Physical features of ultrasound-enhanced heterogeneous permanganate oxidation. Ultrason. Sonochem. 17, 123-131. doi: 10.1016/j.ultsonch.2009.05.011

Kuroki, H., Onishi, K., Asami, K., and Yamaguchi, T. (2019). Catalyst slurry preparation using a hydrodynamic cavitation dispersion method for polymer electrolyte fuel cells. Ind. Eng. Chem. Res. 58, 19545-19550. doi: 10.1021/acs.iecr.9b02111

Lauterborn, W., and Bolle, H. (1975). Experimental investigations of cavitationbubble collapse in the neighbourhood of a solid boundary. J. Fluid Mech. 72, 391-399. doi: 10.1017/S0022112075003448

Mane, M. B., Bhandari, V. M., Balapure, K., and Ranade, V. V. (2020). A novel hybrid cavitation process for enhancing and altering rate of disinfection by use of natural oils derived from plants. Ultrason. Sonochem. 61:104820. doi: 10.1016/j.ultsonch.2019.104820

Maršálek, B., Zezulka, Š., Maršálková, E., Pochylý, F., and Rudolf, P. (2020). Synergistic effects of trace concentrations of hydrogen peroxide used in a novel hydrodynamic cavitation device allows for selective removal of cyanobacteria. Chem. Eng. J. 382:122383. doi: 10.1016/j.cej.2019.122383

Merzkirch, W., Rockwell, D., and Tropea, C. (2015). Orifice Plates and Venturi Tubes. Cham; Heidelberg; New York, NY; Dordrecht; London: Springer International Publishing. Available online at: https://link.springer. com/content/pdf/bfm\%3A978-3-319-16880-7\%2F1.pdf

Milly, P. J., Toledo, R. T., Harrison, M. A., and Armstead, D. (2007). Inactivation of food spoilage microorganisms by hydrodynamic cavitation to achieve pasteurization and sterilization of fluid foods. J. Food Sci. 72, M414-M422. doi: 10.1111/j.1750-3841.2007.00543.x

Milly, P. J., Toledo, R. T., Kerr, W. L., and Armstead, D. (2008). Hydrodynamic cavitation: characterization of a novel design with energy considerations for the inactivation of saccharomyces cerevisiae in apple juice. J. Food Sci. 73, M298-M303. doi: 10.1111/j.1750-3841.2008.00827.x

Mohod, A. V., Gogate, P. R., Viel, G., Firmino, P., and Giudici, R. (2017). Intensification of biodiesel production using hydrodynamic cavitation based on high speed homogenizer. Chem. Eng. J. 316, 751-757. doi: 10.1016/j.cej.2017.02.011

Nabi, M., Zhang, G., Zhang, P., Tao, X., Wang, S., Ye, J., et al. (2019). Contribution of solid and liquid fractions of sewage sludge pretreated by high pressure homogenization to biogas production. Bioresour. Technol. 286:121378. doi: 10.1016/j.biortech.2019.121378

Nagalingam, A. P., Thiruchelvam, V. C., and Yeo, S. H. (2019). A novel hydrodynamic cavitation abrasive technique for internal surface finishing. J. Manuf. Process. 46, 44-58. doi: 10.1016/j.jmapro.20 19.08.014

Panda, D., and Manickam, S. (2019). Hydrodynamic cavitation assisted degradation of persistent endocrine-disrupting organochlorine pesticide dicofol: optimization of operating parameters and investigations on the mechanism of intensification. Ultrason. Sonochem. 51, 526-532. doi: 10.1016/j.ultsonch.2018.04.003

Pandur, Z., Dogsa, I., Dular, M., and Stopar, D. (2020). Liposome destruction by hydrodynamic cavitation in comparison to chemical, physical and mechanical treatments. Ultrason. Sonochem. 61:104826. doi: 10.1016/j.ultsonch.2019.104826

Patil, P. N., Gogate, P. R., Csoka, L., Dregelyi-Kiss, A., and Horvath, M. (2016). Intensification of biogas production using pretreatment based on hydrodynamic cavitation. Ultrason. Sonochem. 30, 79-86. doi: 10.1016/j.ultsonch.2015.11.009
Petkovšek, M., Mlakar, M., Levstek, M. M., StraŽar Širok, B., and Dular, M. (2015). A novel rotation generator of hydrodynamic cavitation for waste-activated sludge disintegration. Ultrason. Sonochem. 26, 408-414. doi: 10.1016/j.ultsonch.2015.01.006

Prajapat, A. L., and Gogate, P. R. (2019). Depolymerization of carboxymethyl cellulose using hydrodynamic cavitation combined with ultraviolet irradiation and potassium persulfate. Ultrason. Sonochem. 51, 258-263. doi: 10.1016/j.ultsonch.2018.10.009

Rahmeyer, W. J. (1981). Cavitation damage to hydraulic structures. J. Am. Water Works Assoc. 73, 270-274. doi: 10.1002/j.1551-8833.1981.tb04703.x

Rajoriya, S., Bargole, S., George, S., Saharan, V. K., Gogate, P. R., and Pandit, A. B. (2019). Synthesis and characterization of samarium and nitrogen doped $\mathrm{TiO}_{2}$ photocatalysts for photo-degradation of 4-acetamidophenol in combination with hydrodynamic and acoustic cavitation. Sep. Purif. Technol. 209, 254-269. doi: 10.1016/j.seppur.2018.07.036

Ross, V., Singh, A., and Pillay, K. (2019). Improved flotation of PGM tailings with a high-shear hydrodynamic cavitation device. Miner. Eng. 137, 133-139. doi: 10.1016/j.mineng.2019.04.005

Saharan, V. K., Badve, M. P., and Pandit, A. B. (2011). Degradation of reactive red 120 dye using hydrodynamic cavitation. Chem. Eng. J. 178, 100-107. doi: 10.1016/j.cej.2011.10.018

Šarc, A., Kosel, J., Stopar, D., Oder, M., and Dular, M. (2018). Removal of bacteria Legionella pneumophila, Escherichia coli, and Bacillus subtilis by (super)cavitation. Ultrason. Sonochem. 42, 228-236. doi: 10.1016/j.ultsonch.2017.11.004

Sarvothaman, V. P., Simpson, A. T., and Ranade, V. V. (2019). Modelling of vortex based hydrodynamic cavitation reactors. Chem. Eng. J. 377:119639. doi: 10.1016/j.cej.2018.08.025

Save, S. S., Pandit, A. B., and Joshi, J. B. (1994). Microbial cell disruption: role of cavitation. Chem. Eng. J. Biochem. Eng. J. 55, B67-B72. doi: 10.1016/0923-0467(94)06062-2

SeŽun, M., Kosel, J., Zupanc, M., Hočevar, M., Vrtovšek, J., Petkovšek, M., et al. (2019). Cavitation as a potential technology for wastewater management - an example of enhanced nutrient release from secondary pulp and paper mill sludge. Stroj. Vestn. J. Mech. Eng. 65:9. doi: 10.5545/sv-jme.2019.6328

Shima, A., Takayama, K., Tomita, Y., and Miura, N. (1981). An Experimental study on effects of a solid wall on the motion of bubbles and shock waves in bubble collapse. Acta Acust. United Ac. 48, 293-301.

Silberrad, D. (1912). Propeller erosion. Engineering 93, 33-35.

Song, L., Yang, J., Yu, S., Xu, M., Liang, Y., Pan, X., et al. (2019). Ultra-high efficient hydrodynamic cavitation enhanced oxidation of nitric oxide with chlorine dioxide. Chem. Eng. J. 373, 767-779. doi: 10.1016/j.cej.2019.05.094

Sun, X., Kang, C. H., Park, J. J., Kim, H. S., Om, A. S., and Yoon, J. Y. (2018a). An experimental study on the thermal performance of a novel hydrodynamic cavitation reactor. Exp. Therm Fluid Sci. 99, 200-210. doi: 10.1016/j.expthermflusci.2018.02.034

Sun, X., Kim, H. S., Yang, S. D., Kim, C. K., and Yoon, J. Y. (2017b). Numerical investigation of the effect of surface roughness on the flow coefficient of an eccentric butterfly valve. J. Mech. Sci. Technol. 31, 2839-2848. doi: 10.1007/s12206-017-0527-0

Sun, X., Kim, S., Yang, S. D., Kim, H. S., and Yoon, J. Y. (2017a). Multiobjective optimization of a Stairmand cyclone separator using response surface methodology and computational fluid dynamics. Powder Technol. 320, 51-65. doi: 10.1016/j.powtec.2017.06.065

Sun, X., Park, J. J., Kim, H. S., Lee, S. H., Seong, S. J., Om, A. S., et al. (2018b). Experimental investigation of the thermal and disinfection performances of a novel hydrodynamic cavitation reactor. Ultrason. Sonochem. 49, 13-23. doi: 10.1016/j.ultsonch.2018.02.039

Sun, X., and Yoon, J. Y. (2018). Multi-objective optimization of a gas cyclone separator using genetic algorithm and computational fluid dynamics. Powder Technol. 325, 347-360. doi: 10.1016/j.powtec.2017.11.012

Sun, X.-H., Li, C.-P., Wong, N.-B., Lee, C.-S., Lee, S.-T., and Teo, B.-K. (2002). Templating effect of hydrogen-passivated silicon nanowires in the production of hydrocarbon nanotubes and nanoonions via sonochemical reactions with common organic solvents under ambient conditions. J. Am. Chem. Soc. 124, 14856-14857. doi: 10.1021/ja0283706

Suslick, K. S. (1990). Sonochemistry. Science 247, 1439-1445. doi: $10.1126 /$ science.247.4949.1439 
Suslick, K. S., Hammerton, D. A., and Cline, R. E. (1986). Sonochemical hot spot. J. Am. Chem. Soc. 108, 5641-5642. doi: 10.1021/ja00278a055

Taniguchi, N. (1974). "On the basic concept of nanotechnology,"in Proceeding of the ICPE (Tokyo), 18-23.

Tao, Y., Cai, J., Huai, X., and Liu, B. (2018). A novel antibiotic wastewater degradation technique combining cavitating jets impingement with multiple synergetic methods. Ultrason. Sonochem. 44, 36-44. doi: 10.1016/j.ultsonch.2018.02.008

Terán Hilares, R., dos Santos, J. G., Shiguematsu, N. B., Ahmed, M. A., da Silva, S. S., and Santos, J. C. (2019). Low-pressure homogenization of tomato juice using hydrodynamic cavitation technology: effects on physical properties and stability of bioactive compounds. Ultrason. Sonochem. 54, 192-197. doi: $10.1016 /$ j.ultsonch.2019.01.039

Thompson, L. H., and Doraiswamy, L. K. (1999). Sonochemistry: science and engineering. Ind. Eng. Chem. Res. 38, 1215-1249. doi: 10.1021/ie9804172

Torabi Angaji, M., and Ghiaee, R. (2015). Decontamination of unsymmetrical dimethylhydrazine waste water by hydrodynamic cavitationinduced advanced fenton process. Ultrason. Sonochem. 23, 257-265. doi: 10.1016/j.ultsonch.2014.09.007

Vajnhandl, S., and Majcen Le Marechal, A. (2005). Ultrasound in textile dyeing and the decolouration/mineralization of textile dyes. Dyes Pigments 65, 89-101. doi: $10.1016 /$ j.dyepig.2004.06.012

Viculis, L. M., Mack, J. J., and Kaner, R. B. (2003). A chemical route to carbon nanoscrolls. Science 299:1361. doi: 10.1126/science.1078842

Vogel, A., Lauterborn, W., and Timm, R. (1989). Optical and acoustic investigations of the dynamics of laser-produced cavitation bubbles near a solid boundary. J. Fluid Mech. 206, 299-338. doi: 10.1017/S0022112089002314

Waghmare, A., Nagula, K., Pandit, A., and Arya, S. (2019). Hydrodynamic cavitation for energy efficient and scalable process of microalgae cell disruption. Algal Res. 40:101496. doi: 10.1016/j.algal.2019.101496

Wang, X., Jia, J., and Wang, Y. (2010). Electrochemical degradation of reactive dye in the presence of water jet cavitation. Ultrason. Sonochem. 17, 515-520. doi: $10.1016 /$ j.ultsonch.2009.10.023

Wang, X., Jia, J., and Wang, Y. (2011). Degradation of C.I. reactive red 2 through photocatalysis coupled with water jet cavitation. J. Hazard. Mater. 185, 315-321. doi: 10.1016/j.jhazmat.2010.09.036

Wang, Z., Xu, X., Kim, J., Malgras, V., Mo, R., Li, C., et al. (2019). Nanoarchitectured metal-organic framework/polypyrrole hybrids for brackish water desalination using capacitive deionization. Mater. Horiz. 6, 1433-1437. doi: 10.1039/C9MH00306A

Wu, Z., Tagliapietra, S., Giraudo, A., Martina, K., and Cravotto, G. (2019). Harnessing cavitational effects for green process intensification. Ultrason. Sonochem. 52, 530-546. doi: 10.1016/j.ultsonch.2018.12.032

Xu, X., Tan, H., Wang, Z., Wang, C., Pan, L., Kaneti, Y. V., et al. (2019). Extraordinary capacitive deionization performance of highly-ordered mesoporous carbon nano-polyhedra for brackish water desalination. Environ. Sci. Nano 6, 981-989. doi: 10.1039/C9EN00017H

Yan, Y., and Thorpe, R. B. (1990). Flow regime transitions due to cavitation in the flow through an orifice. Int. J. Multiphase Flow 16, 1023-1045. doi: 10.1016/0301-9322(90)90105-R

Yi, C., Lu, Q., Wang, Y., Wang, Y., and Yang, B. (2018). Degradation of organic wastewater by hydrodynamic cavitation combined with acoustic cavitation. Ultrason. Sonochem. 43, 156-165. doi: 10.1016/j.ultsonch.2018.01.013

Zhang, Y., Tian, Y., Zhang, Z., and Lin, S. (2018). Experimental and numerical study of cavitating flow with suction in a mixing reactor for water treatment. Chem. Eng. J. 353, 796-804. doi: 10.1016/j.cej.2018.07.183

Zielinski, M., Debowski, M., Kisielewska, M., Nowicka, A., Rokicka, M., and Szwarc, K. (2019). Cavitation-based pretreatment strategies to enhance biogas production in a small-scale agricultural biogas plant. Energy Sust. Dev. 49, 21-26. doi: 10.1016/j.esd.2018.12.007

Zupanc, M., Kosjek, T., Petkovšek, M., Dular, M., Kompare, B., Širok, B., et al. (2014). Shear-induced hydrodynamic cavitation as a tool for pharmaceutical micropollutants removal from urban wastewater. Ultrason. Sonochem. 21, 1213-1221. doi: 10.1016/j.ultsonch.2013.10.025

Conflict of Interest: The authors declare that the research was conducted in the absence of any commercial or financial relationships that could be construed as a potential conflict of interest.

Copyright $\odot 2020$ Sun, Chen, Liu, Zhao and Yoon. This is an open-access article distributed under the terms of the Creative Commons Attribution License (CC BY). The use, distribution or reproduction in other forums is permitted, provided the original author(s) and the copyright owner(s) are credited and that the original publication in this journal is cited, in accordance with accepted academic practice. No use, distribution or reproduction is permitted which does not comply with these terms. 